\title{
Prevalence and factors associated with abdominal obesity among primary health care professional nurses in Eastern Cape, South Africa
}

\author{
Sizeka Monakali, Daniel Ter Goon, Eunice Seekoe and Eyitayo Omolara Owolabi* \\ Faculty of Health Sciences, Department of Nursing Science, University of Fort Hare, East London, South Africa \\ ${ }^{*}$ Corresponding author, email: owolabiomolara101@gmail.com
}

Background: Nurses are key stakeholders in health promotion and obesity management, yet a high-risk group for obesity development. This study examined the prevalence and correlates of abdominal obesity among primary health care professional nurses (PHCPNs) in Eastern Cape, South Africa.

Methods: This cross-sectional study involved 203 PHCPNs conveniently selected across 41 primary health care facilities in Eastern Cape, South Africa. The WHO STEPwise questionnaire was used for data collection. Abdominal obesity was defined according to the WHO criteria as a waist circumference $\geq 94 \mathrm{~cm}$ for men and $\geq 80 \mathrm{~cm}$ for women or waist-to-hip ratio $\geq 0.90$ in men and $\geq 0.85$ in women; and a waist-to-height ratio of $>0.50$.

Results: The prevalence of abdominal obesity ranged from $50 \%$, to $87 \%$ to $90 \%$, using waist-to-hip ratio, waist circumference and waist-to-height ratio, respectively. Age, gender and duration of practice were significantly associated with abdominal obesity. After adjusting for potential confounders, only age $>30$ years $(\mathrm{OR}=6.7 ; 95 \% \mathrm{Cl}=2.4-18.7 ; p<0.001)$ and female sex $(\mathrm{AOR}=7.9$; $95 \% \mathrm{Cl}=2.4-18.7 ; p<0.001$ ) were independent predictors of obesity.

Conclusion: There is a high prevalence of abdominal obesity among PHCPNs in Eastern Cape, South Africa, which was associated with female sex and ageing. This constitutes a potential risk for the healthcare workforce of the province and might be an impediment to adequate conveyance to patients of health education on healthy weight management by the affected nurses. There is an urgent need for appropriate workplace health policies targeted towards the promotion of physical activities, healthy lifestyle and ultimately weight reduction among this group.

Keywords: abdominal obesity, health promotion, nurses, obesity, prevalence, South Africa

\section{Introduction}

Obesity is a leading cause of morbidity and mortality and is increasingly becoming a global public health threat. ${ }^{1}$ Currently, more than half a billion adults are obese worldwide with an observed faster rate of growth in the developing countries.1, 2 South Africa is not excluded from this burden and has a documented higher prevalence of obesity compared with many other African and developing countries., ${ }^{3,4}$ Even though general obesity poses a significant threat to the health of individuals, abdominal obesity pose a greater risk. ${ }^{5}$ The risk conferred by abdominal obesity is not only limited to cardiovascular health, but also impacts on the metabolic health of an individual, as well as predisposing to the development of certain cancers. ${ }^{6}$

Healthcare professionals have significant roles to play in promoting a healthy lifestyle of their care receivers as well as the community at large. However, they have been acknowledged as a high-risk group for obesity development., ${ }^{7,8}$ Obesity, particularly abdominal obesity, does not only affect the nurses individually; it also has a potential impact on their confidence in caring and educating patients with similar conditions. ${ }^{9}$ Aside from the workrelated stress and unhealthy dietary practices implicated as underlying factors, the night shift has been particularly identified as contributing to abdominal obesity among this cohort.7, 10, 11 Studies on the burden of obesity and abdominal obesity among nurses are limited to secondary and tertiary health institutions that rotate or run night shifts, ${ }^{1,7,10-13}$ in neglect of nurses who do not rotate or run night shifts. Thus, this study aimed at determining the prevalence and factors associated with abdominal obesity among primary health care professional nurses in the Eastern Cape, South Africa. Such information will assist in determining the level of burden among this cohort who do not rotate shifts as this will also help us to understand if abdominal obesity is peculiar to night-shift nurses and those who rotate shifts only, as documented in the literature. This might assist in crafting effective and appropriate public health and workplace policies.

\section{Methods}

\section{Study design}

A quantitative, descriptive and cross-sectional approach was used to screen for abdominal obesity among primary health care nurses in the Eastern Cape Province.

\section{Study setting and sample}

A total of 203 nurses were accessible during the course of the study which spanned through February to May 2017. These nurses were selected from 41 primary health care facilities in the Province. The Eastern Cape is one of the nine provinces of South Africa, with its capital in Bisho. It was created in 1994 from the Xhosa homelands of Transkei and Ciskei together with the eastern segment of the Cape Province. It is the traditional home of the Xhosa people. The province is made up of two metropolitan municipalities - Buffalo City Metropolitan Municipality (BCMM) and Nelson Mandela Metropolitan Municipality - and six districts - Amathole, Joe Gqabi, OR Tambo, Sarah Bartman and Chris Hani and Alfred Ndzo. ${ }^{14}$

A convenience sampling method was used to select the primary health care centres from four randomly selected districts (OR Tambo, Buffalo City Metropolitan, Chris Hani and Sarah Baartman). There are approximately 880 nurses in the selected districts due to staff shortage, especially in rural districts like OR 
Tambo (OR Tambo $=250$, Chris Hani $=230$, Sarah Baartman $=100$ and BCMM 300). At a confidence level of $95 \%$, a sample size of 268 nurses is required. However, only 203 were available and accessible. Only practising professional nurses aged 18 years and above were included in the study. The pregnant nurses were excluded as a result of effect on obtaining anthropometric measurements.

\section{Ethical consideration}

Ethical clearance was obtained from the university ethical committee (Reference number; EC-2015RP10-426), Provincial Health Department, sub-district managers as well as the facility heads. Informed consent was obtained from all participants. The rights to anonymity and confidentiality were ensured throughout the course of the study.

\section{Study instrument}

The modified WHO STEPwise instrument was used for obtaining data on demographic and behavioural characteristics of the clients. The instrument was pilot tested among 20 nurses in a separate district from those included in the main study.

\section{Data collection}

Data was collected using a face-to-face interview method. The data obtained included demographic and behavioural variables such as smoking, alcohol use and physical activity, which were obtained via self-reporting. Physical activity level was defined based on the WHO recommendations of at least 150 minutes of moderate-intensity physical activities or 75 minutes of vigorousintensity activities per week. Those who reported not engaging in any activities were defined as not active, those who engage but do not meet the recommendations were classified as less active while those who did were regarded as active. Alcohol use and smoking status was simply defined as a self-reported use of alcohol and tobacco product in the last 30 days, respectively, using a Yes/No response. Anthropometric measurements (waist circumference (WC), weight, height and hip circumference) were also taken, following a standard method..$^{15}$ For measuring the weight and the height of the participants, a SECA weighing scale and stadiometer (Hamburg, Germany) were used throughout the study for consistency. All measurements were taken by a professional nurse trained in anthropometric measurements. Abdominal obesity was defined according to the WHO criteria ${ }^{16}$ as a WC $\geq 94 \mathrm{~cm}$ for men and $\geq 80 \mathrm{~cm}$ for women or waist-to-hip ratio (WHR) $\geq 0.90$ in men and $\geq 0.85$ in women; and a WHTR of $>$ $0.50 .^{17}$

\section{Data analysis}

Data were expressed as mean values, standard deviation, minimum and maximum for continuous variables and counts and proportions for categorical variables. Percentages were compared with a chi-square test. Descriptive and inferential statistics were used for determining the prevalence and determinants of abdominal obesity among the study participants. A $p$-value of $<0.05$ was considered statistically significant. All analysis was done with the Statistical Package for the Social Sciences (SPSS ${ }^{\circledR}$ ), version 23 (IBM Corp, Armonk, NY, USA).

\section{Results}

A total of 203 participants were included in the analysis. The average age of the study participants was 45.17 (SD \pm 11.26 ) years while the average duration of practice was 15.98 $(S D \pm 11.07)$ years. Almost half of the participants were married
Table 1: Socio-demographic characteristics of participants by gender

\begin{tabular}{|c|c|c|c|}
\hline Variables & $A(I I$ & Female & Male \\
\hline \multicolumn{4}{|l|}{ Age (years): } \\
\hline $21-30$ & $26(12.8)$ & $19(10.6)$ & $7(29.2)$ \\
\hline $31-40$ & $50(24.6)$ & $41(22.9)$ & $9(37.5)$ \\
\hline $41-50$ & $42(20.7)$ & $39(21.8)$ & $3(12.5)$ \\
\hline $51-60$ & $74(36.5)$ & $69(38.5)$ & $5(20.8)$ \\
\hline $61-70$ & $11(5.4)$ & $11(6.1)$ & $0(0.0)$ \\
\hline \multicolumn{4}{|l|}{ Marital status: } \\
\hline Single & $83(40.9)$ & $71(39.7)$ & $12(50.0)$ \\
\hline Married & $101(49.8)$ & $90(50.3)$ & $11(45.8)$ \\
\hline Divorced & $9(4.4)$ & $9(5.0)$ & $0(0.0)$ \\
\hline Separated & $1(0.5)$ & $1(0.6)$ & $0(0.0)$ \\
\hline Widow/widower & $9(4.4)$ & $8(4.5)$ & $1(4.2)$ \\
\hline \multicolumn{4}{|l|}{ Number of children: } \\
\hline 1 & $37(20.4)$ & $33(20.4)$ & $4(21.1)$ \\
\hline 2 & $61(33.7)$ & $58(35.8)$ & $3(15.8)$ \\
\hline 3 & $58(32.0)$ & $49(30.2)$ & $9(47.4)$ \\
\hline 4 & $18(9.9)$ & $16(9.9)$ & $2(10.5)$ \\
\hline 5 & $5(2.8)$ & $5(3.1)$ & $0(0.0)$ \\
\hline 6 & $1(0.6)$ & $1(0.6)$ & $0(0.0)$ \\
\hline 7 & $1(0.6)$ & $0(0.0)$ & $1(5.3)$ \\
\hline \multicolumn{4}{|l|}{ Level of education: } \\
\hline Diploma & $132(65.0)$ & $117(65.4)$ & $15(62.5)$ \\
\hline Degree & $67(33.0)$ & $58(32.4)$ & $9(37.5)$ \\
\hline Postgraduate Diploma & $3(1.5)$ & $3(1.7)$ & $0(0.0)$ \\
\hline Masters & $1(0.5)$ & $1(0.6)$ & $0(0.0)$ \\
\hline \multicolumn{4}{|l|}{ Race: } \\
\hline Black & $195(96.1)$ & $171(95.5)$ & $24(100.0)$ \\
\hline Coloured & $8(3.9)$ & $8(4.5)$ & $0(0.0)$ \\
\hline \multicolumn{4}{|l|}{ Duration of practice: } \\
\hline $1-10$ years & $72(40.7)$ & $59(38.1)$ & $13(59.1)$ \\
\hline $11-20$ years & $41(23.2)$ & $37(23.9)$ & $4(18.2)$ \\
\hline $21-30$ years & $44(24.9)$ & $41(26.5)$ & $3(13.6)$ \\
\hline 31 and above & $20(11.3)$ & $18(11.6)$ & $2(9.1)$ \\
\hline \multicolumn{4}{|l|}{ Income (Rand): } \\
\hline $10000-15000$ & 65 (39.4) & $55(38.5)$ & $10(45.5)$ \\
\hline Above 15,000 & $100(60.6)$ & $88(61.5)$ & $12(54.5)$ \\
\hline
\end{tabular}

$(49.8 \%)$ or single $(40.9 \%)$ and had a diploma certificate in nursing (65.0\%), and were earning more than R15 000 (60.6\%) (Table 1).

The prevalence of abdominal obesity using various anthropometric indicators among the study participants revealed varying results. The prevalence of abdominal obesity ranged from $50.0 \%$, to $87.0 \%$ to $90.0 \%$, using waist-to-hip ratio, waist circumference and waist-to-height ratio, respectively.

As shown in Table 2, gender, level of education, age and duration of practice were the socio-demographic factors associated with abdominal obesity (derived from WC) among the study participants.

Shown in Table 3 are the independent predictors of abdominal obesity. After adjusting for potential confounding variables, only 
Table 2: Association between abdominal obesity and sociodemographic variables

\begin{tabular}{|c|c|c|c|}
\hline Variables & Abdominally obese & Not obese & $p$-value \\
\hline \multicolumn{4}{|l|}{ Gender: } \\
\hline Male & $13(54.2)$ & $11(45.8)$ & $<0.001$ \\
\hline Female & $164(91.6)$ & $15(8.4)$ & \\
\hline \multicolumn{4}{|l|}{ Level of education: } \\
\hline Diploma & $12(9.1)$ & $120(90.9)$ & 0.011 \\
\hline Degree & $12(17.9)$ & $55(82.1)$ & \\
\hline Postgraduate diploma & $1(33.3)$ & $2(66.7)$ & \\
\hline Masters & $1(100.0)$ & $0(0.0)$ & \\
\hline \multicolumn{4}{|l|}{ Age (years): } \\
\hline $\begin{array}{l}\text { Less than or equal } \\
\text { to } 30\end{array}$ & $15(57.7)$ & $11(42.3)$ & $<0.001$ \\
\hline More than 30 & $162(91.5)$ & $15(8.5)$ & \\
\hline \multicolumn{4}{|l|}{$\begin{array}{l}\text { Duration of practice } \\
\text { (years): }\end{array}$} \\
\hline More than 10 & $57(79.2)$ & $15(20.8)$ & 0.005 \\
\hline $\begin{array}{l}\text { Less than or equal } \\
\text { to } 10\end{array}$ & $98(93.3)$ & $7(6.7)$ & \\
\hline \multicolumn{4}{|l|}{ Income (Rand): } \\
\hline $10000-15000$ & $54(83.1)$ & $11(16.9)$ & 0.144 \\
\hline Above 15000 & $90(90.0)$ & $10(10.0)$ & \\
\hline \multicolumn{4}{|l|}{ Marital status: } \\
\hline Never married & $69(83.1)$ & $149(16.9)$ & 0.111 \\
\hline Ever married & $108(90.0)$ & $12(10.0)$ & \\
\hline \multicolumn{4}{|l|}{ Physical activity: } \\
\hline Inactive & $60(90.9)$ & $6(9.1)$ & 0.256 \\
\hline Less active & $69(88.5)$ & $9(11.5)$ & \\
\hline Active & $48(81.4)$ & $11(18.6)$ & \\
\hline \multicolumn{4}{|l|}{ Alcohol consumption: } \\
\hline Yes & $30(83.3)$ & $6(16.7)$ & 0.069 \\
\hline No & $13(61.9)$ & $8(38.1)$ & \\
\hline \multicolumn{4}{|l|}{ Smoking: } \\
\hline Yes & $5(62.5)$ & $3(27.5)$ & 0.557 \\
\hline No & $9(64.3)$ & $4(30.8)$ & \\
\hline
\end{tabular}

Table 3: Logistic regression showing independent predictors of abdominal obesity

\begin{tabular}{|c|c|c|c|c|c|}
\hline Variables & Beta & Wald & SE & OR (95\%CI) & $p$-value \\
\hline \multicolumn{6}{|l|}{ Gender: } \\
\hline Female & 2.10 & 15.40 & 0.50 & $7.9(2.80-22.30)$ & $<0.001$ \\
\hline \multicolumn{6}{|l|}{ Male (reference) } \\
\hline \multicolumn{6}{|l|}{ Age (years): } \\
\hline Above 30 years & 1.90 & 13.30 & 0.50 & $6.7(2.40-18.70)$ & $<0.001$ \\
\hline $\begin{array}{l}\leq 30 \text { years (refer- } \\
\text { ence) }\end{array}$ & & & & & \\
\hline
\end{tabular}

gender and age were independent predictors of abdominal obesity among the study participants. Female nurses were eight times more likely to be obese than their male colleagues and those above the age of 30 years were about seven times more likely to be abdominally obese compared to those below 30 years.

\section{Discussion}

This study sought to determine the prevalence of abdominal obesity among primary healthcare professional nurses in the Eastern Cape Province of South Africa. This study revealed an alarming prevalence of abdominal obesity among these professional nurses, ranging from $50 \%$ to as high as $90 \%$ using various anthropometric measures. The prevalence documented among nurses in this setting is double the prevalence $(25.4 \%)$ recorded among nurses in Ghana ${ }^{12}$ and Poland (22.0-31.0\%) using various criteria. The findings in this setting is comparable only to the prevalence reported among nurses in Vhembe and Capricorn Districts in the Limpopo Province of South Africa, which ranged from $56.5 \%$ to $80.5 \% .^{13}$ Knowing full well that abdominal obesity increases the likelihood of developing chronic illnesses and other conditions, ${ }^{5,6}$ this worrisome finding shows that the health of these important stakeholders in this setting might be compromised in the very near future, if not already compromised. Also, the suitability as well as level of confidence of these abdominally obese nurses in counselling patients with similar condition is also questionable. ${ }^{9}$ Even if they do, the obese patients might not be receptive to ideas and counsel received from nurses with similar problems. ${ }^{9}$ The fact that a large number of these nurses are abdominally obese is more disturbing and therefore calls for urgent workplace programmes targeted at promoting physical activities and other healthy lifestyles among this cohort.

Several reasons have been postulated to be underlying the high burden of abdominal obesity among nurses. While some authors ${ }^{7}, 10-13$ identified the nature of work of nurses, particularly rotating and night shifts, some associated this with lesser participation in physical activity and poor dietary practices of nurses while on duty. ${ }^{12,18}$ Although the current study did not obtain data on the previous work experiences of these primary health care nurses, so we cannot categorically state that the recorded association between night shifts and obesity among nurses does not hold true among our participants as they do not rotate or run night shifts. However, this finding shows that the burden of abdominal obesity is a general problem among nurses and not just those who rotate or run night shifts. Other identified factors might also be responsible for the high prevalence found in this setting, including their dietary pattern, which was not investigated in this study.

We found female sex and age above 30 years as the significant and independent predictors of abdominal obesity among the study participants. This is not against the norm as several studies have already reported similar associations..$^{10,12,13,19-21}$ The higher odds for developing obesity among females has been linked to engagement in lesser physical activities compared to men. ${ }^{22,23}$ Even so, our study found no significant association between physical activity and abdominal obesity among the study participants, though participants who were considered active had a lesser prevalence of abdominal obesity. Not forgetting that other factors such as genetics and diets also contribute to obesity development, ${ }^{24}$ physiological changes occurring during the reproductive years might have also contributed to the observed higher prevalence among the female nurses. ${ }^{25}$

Finally, female nurses who were aged above 30 years had a higher prevalence of abdominal obesity compared to those who were 30 years old and below. This is not contrary to several other studies. $^{10,12,20}$ The higher prevalence found among the older nurses might be associated with the accompanying longer duration of practice as well as higher level of experience. Thus, 
they engage more in consultations with lesser participation in more strenuous activities while the younger nurses are usually involved in such. Aside to the work environment, engagement in lesser physical activities might also be found among the older nurses, resulting in the development of abdominal obesity.

To the best knowledge of the authors, this is the first study on abdominal obesity among professional primary health care nurses in South Africa, which highlights the weight status of the professional primary health nurses who are health promotors in the rural settings of the province. However, the study was confined to only one province, thus its findings cannot be generalised to all South African nurses. Also, the cross-sectional nature and the convenience sampling of the clinics are limitations to the study even though the districts were randomly selected.

\section{Strengths and limitations}

This is the first study, to our knowledge, to assess the prevalence and associated factors of abdominal obesity among primary health care professional nurses in the Eastern Cape region of South Africa, using various anthropometric measures. The findings of this study provide a snapshot of the burden of abdominal obesity among this important population involved in health promotion. Also, the coverage of several primary health care clinics gives credence to this study. However, the convenience sampling, cross-sectional nature and the small sample size are obvious limitations. We also did not cover all the primary health care clinics in the region, therefore we might not be able to generalise the findings of this study to all primary health care professional nurses in the region.

\section{Conclusion}

There is a high prevalence of abdominal obesity among primary health care professional nurses in the Eastern Cape Province of South Africa. This portends great risk for the healthcare workforce of the Province. Also, this study establishes that the problem of abdominal obesity might not necessarily be peculiar to nurses rotating shifts or involved in night shifts. There is an urgent need for workplace health policies that will promote physical activity and healthy lifestyle behaviour, as well as maintenance of healthy weight, for nurses in this setting, particularly females and those in the older age groups.

Availability of data and material - The data from this study will only be made available by the author on request.

Authors' contributions - SM, DTG and ES conceptualised and designed the study. EOO participated in data collection and analysis. EOO, SM and DTG drafted the manuscript. All authors read and approved the final manuscript.

Conflicts of interests - The authors declare no conflict of interest.

Funding - SM received study grants from the Health and Welfare Sector Education and Training Authority, South Africa, for the implementation of the project.

Acknowledgements - The authors are grateful to the management and nursing staff of the three health facilities for their support towards the successful implementation of the project.

\section{References}

1. WHO. Obesity and overweight factsheet [Internet]. Geneva: World Health Organisation; 2017 [cited 2017 Jul 8]. Available from: http:// www.who.int/mediacentre/factsheets/fs311/en/.
2. Finucane MM, Steven GA, Cowen MJ, et al. National, regional, and global trends in body - mass index since 1980: systematic analysis of health examination surveys and epidemiological studies with 960 country - years and 9.1 million participants. Lancet. 2011;377(9765): 557-567. doi:10.1016/s0140-6736(10)62037-5.

3. Murray C, $\mathrm{Ng} \mathrm{M}$. Nearly one-third of the world's population is obese or overweight, new data shows. Institute of Health Metrics and Evaluation [Internet]. [Cited 2017 Jun 1]. Available from: http://www. healthdata.org/news-release/nearly-one-third-world\%E2\%80\%99spopulation-obese-or-overweight-new-data-show.

4. Dalal S, Beunza JJ, Volmink J, et al. Non-communicable diseases in sub-Saharan Africa : what we know now. Int J Epidemiol. 2011;40: 885-901. doi:10.1093/ije/dyr050.

5. Marfell-Jones N, Olda T, Stew A. International standards for anthropometric assessment. Australia: The international Society for the Advancement of Kinanthropometry; 2006.

6. Bastien $M$, Poirier $P$, Lemieux I, Després JP. Overview of epidemiology and contribution of obesity to cardiovascular disease. Prog Cardiovasc Dis. 2014;56: 369-381. https://doi.org/10.1016/j.pcad.2013.10.016

7. Zhang C, Rexrode KM, Van Dam RM, Li TY, Hu F. Abdominal obesity and the risk of all-cause cardiovascular, and cancer mortality; Sixteen year of follow-up in US women. Circulation. 2008;117: 1658-1667. doi:10.1161/circulationaha.107.739714.

8. Kim M-J, Son K-H, Park H-Y, et al. Association between shift work and obesity among female nurses: Korean Nurses' Survey. BMC Public Health. 2013;13: 78. doi:10.1186/1471-2458-13-1204

9. Bogossian FE, Hepworth J, Leong GM, et al. A cross sectional analysis of patterns of obesity in a cohort of working nurses and midwives in Australia, New Zealand and the United Kingdom. Int J Nurs Stud. 2012;49: 727-738. doi:10.1016/j.jinurstu.2012.01.003.

10. Kyle RG, Neall RA, Atherton JM. Prevalence of overweight and obesity among nurses in Scotland: A cross-sectional study using the Scottish Health Survey. Int J Nurs Stud. 2016;53: 126-133. doi:10.1016/j. ijnurstu.2015.10.015.

11. Lee G-Y, Kim K, Kim S-Y, et al. Effects of shift work on abdominal obesity among 20-39 year-old female nurses: a 5-year retrospective longitudinal study. An Occup Env Med. 2016;28: 78. doi:10.1186/ s40557-016-0148-6.

12. Peplonska B, Bukowska A, Sobala W. Association of rotating night shift work with $\mathrm{BMI}$ and abdominal obesity among nurses and midwives. PLoS ONE 2015;10(7): e0133761. doi:10.1371/journal.pone.0133761.

13. Aryee PA, Helegbe GK, Baah J, Sarfo-Asante RA, Quist-Therson R. Prevalence and risk factors for overweight and obesity among nurses in the Tamale Metropolis of Ghana. J Med Biomed Sci. 2013;2(4): 1323. doi:10.4314/jmbs.v2i4.3.

14. Goon DT, Maputle MS, Olukoga A, Lebese R, Khoza LB, Anyanwu FC. Overweight, obesity and underweight in nurses in Vhembe and Capricorn Districts, Limpopo, South Africa. S Afr J Clin Nutr. 2013;26: 147-149. doi:10.1080/16070658.2013.11734459.

15. Stats SA. Statistics. South Africa. Statistics South Africa 2011;1-190. Available from: http://www.statssa.gov.za/publications/SAStatistics/ SAStatistics2011.pdf.

16. World Health Organisation. Waist circumference and waist-hip ratio. Geneva: Report of a WHO Expert Consultation; 2011.

17. Ashwell M, Gibson S. Waist-to-height ratio is a simple and effective obesity screening tool for cardiovascular risk factors: analysis of data from the British National Diet and Nutrition Survey of adults aged 19-64 years. Obes Facts. 2009;2: 97-103. doi:10.1159/000203363.

18. Phiri LP, Draper CE, Lambert EV, Kolbe-Alexander TL. Nurses' lifestyle behaviours, health priorities and barriers to living a healthy lifestyle: a qualitative descriptive study. BMC Nurs. 2014;13: 47. doi:10.1016/j. jsams.2014.11.368.

19. Adeniyi O, Longo-Mbenza B, Goon D. Female sex, poverty and globalization as determinants of obesity among rural South African type 2 diabetics: a cross-sectional study. BMC Public Health 2015;15: 3387. doi:10.1186/s12889-015-1622-8.

20. Owolabi EO, Goon DT, Adeniyi OV, Adedokun AO, Seekoe E. Prevalence and associated factors of obesity among South African adults: A Cross-sectional study. Online J Health Allied Sci. 2017;16(2): 1. doi:10.1080/20786190.2017.1340251.

21. Owolabi EO, Goon DT, Adeniyi OV. Central obesity and normal-weight central obesity among adults attending healthcare facilities in Buffalo 
City Metropolitan Municipality, South Africa: a cross-sectional study. I. J Health, Popul Nutr. 2017;36: 407. https://doi.org/10.1186/s41043017-0133-x

22. JakicicJ,OttoA,LossW.Physicalactivity considerationsforthetreatment and prevention of obesity. Am J Clin Nutr. 2005;82(1): 226S-229S. https://doi.org/10.1093/ajcn/82.1.226S

23. Chukwuonye I, Chuku A, John C, Ohagwu KA, Imoh ME, Isa $\mathrm{SE}$, et al. Prevalence of overweight and obesity in adult Nigerians - a systematic review. Diabetes Metab Syndr. 2013, 6, 43-47. https://doi.org/10.2147/dmso.s38626. https://doi.org/10.2147/DMSO
24. Mathieu P, Lemieux I, Després J. Obesity, Inflammation, and cardiovascular risk. Clin Pharmacol Ther. 2010;87(4): 407-416. doi:10.1038/clpt.2009.311.

25. Gunderson E. Childbearing and obesity in women: weight before, during, and after pregnancy. Obstet Gyneacol Clin North Am. 2009;36(2): 317-332. doi:10.1016/j.ogc.2009.04.001.

Received: 23-01-2018 Accepted: 12-04-2018 